Linha D'Água (Online), São Paulo, v. 33, n. 2, p. 189-214, maio-ago. 2020

\title{
RESENHAS DOS LIVROS DIDÁTICOS DO GUIA PNLD 2020 DE LÍNGUA PORTUGUESA: UMA FERRAMENTA PARA O TRABALHO DOCENTE
}

\author{
PORTUGUESE LANGUAGE PNLD 2020 GUIDE TEXTBOOK \\ REVIEWS: A TOOL FOR TEACHING WORK
}

\section{Daniella Barbosa Buttler*}

Centro Universitário Senac e Faculdade de Tecnologia do Estado de São Paulo, São Paulo, SP, Brasil

Maria Izabel Rodrigues Tognato*

Universidade Estadual do Paraná, Campus de Campo Mourão, PR, Brasil

\begin{abstract}
Resumo: Considerando o contexto sócio-histórico mais amplo em que temos vivido em relação ao uso do livro didático na Educação Básica da rede pública de ensino, buscamos contribuir para um debate social acerca do processo de escolha dos livros didáticos nas escolas e 0 Guia PNLD 2020, uma vez que o documento oferece resenhas a respeito dos livros didáticos de Língua Portuguesa aprovados, bem como sobre as possíveis relações que o Guia PNLD 2020 estabelece com os saberes e as Capacidades Cocentes (HOFSTETTER; SCHNEUWLY, 2009; STUTZ, 2012), além das capacidades de linguagem (DOLZ; PASQUIER; BRONCKART, 1993; SCHNEUWLY; DOLZ, 2004; STUTZ; CRISTOVÃ0, 2011; (RISTOVÃ0, 2013), necessários ao ensino de línguas. Para tanto, pautamos nosso estudo na perspectiva teóricometodológica do Interacionismo Sociodiscursivo (ISD) (BRONCKART, [1997]2009). Quanto aos procedimentos metodológicos, utilizamos 0 Guia PNLD 2020 como objeto de análise no que tange às Resenhas dos livros aprovados pelo PNLD 2020, tomando as capacidades de linguagem, os saberes e as Capacidades Docentes como categorias de análise destas Resenhas. Os resultados apontam para possíveis contribuições e/ou limitações do Guia PNLD 2020 para 0 ensino de Língua Portuguesa. Com isso, esperamos contribuir para a discussão acerca do processo de avaliação e escolha do livro didático pelo professor de línguas.
\end{abstract}

Palavras-chave: língua portuguesa; interacionismo sociodiscursivo; resenhas dos livros didáticos aprovados; trabalho docente.

Abstract: Considering the broader socio-historical context in which we have lived in the relation to the use of textbooks in Basic Education, in the public school system, we seek to contribute to a social debate about the process of choosing textbooks in schools and the National Book and Didactic Material Program (PNLD) 2020 Guide, since the document offers reviews about approved Portuguese

* Professora doutora do Centro Universitário Senac e da Faculdade de Tecnologia do Estado de São Paulo - FATEC, São Paulo, SP, Brasil; https://orcid.org/0000-0002-4138-7358;

daniellabar@gmail.com

** Professora doutora da Universidade Estadual do Paraná - UNESPAR, Campus de Campo Mourão, PR, Brasil; http://orcid.org/0000-0003-3705-0354; maria.tognato@unespar.edu.br

http://dx.doi.org/10.11606/issn.2236-4242.v33i2p189-214 
Linha D'Água (Online), São Paulo, v. 33, n. 2, p. 189-214, maio-ago. 2020

language textbooks, as well as about the possible relationships that the PNLD 2020 Guide establishes with teaching knowledge and abilities (HOFSTETTER; SCHNEUWLY, 2009; STUTZ, 2012), in addition to language skills (DOLZ; PASQUIER; BRONCKART, 1993; SCHNEUWLY; DOLZ, 2004; STUTZ; CRISTOVÃO, 2011; (RISTOVÃO, 2013), fundamental for language teaching. Nevertheless, we guided our study according to the theoretical-methodological perspective of the Socio-discursive Interactionism (ISD) (BRONCKART, 1997/2009). As for the methodological procedures, we used the PNLD 2020 Guide as an object of analysis in regard to Reviews of approved books by PNLD 2020, taking language skills, knowledge and teaching abilities as categories of analysis of those Reviews. The results lead us to possible contributions and / or limitations of the PNLD 2020 Guide for the teaching of Portuguese. Having said that, we hope to contribute to the discussion about the evaluation process of choosing textbooks by the language teacher.

Keywords: Portuguese Language; Socio-discursive Interactionism; Reviews of Approved Textbooks; Teaching Work.

\section{Introdução}

O Programa Nacional do Livro Didático (PNLD) ${ }^{1}$, como política de provimento de materiais para o ensino adotada pelo governo federal e como um agente social contribui para o envio de livros didáticos (de todas as disciplinas) a serem utilizados na educação básica nas escolas públicas brasileiras. As obras são encomendadas por editoras a diferentes autores, que produzem os livros didáticos por iniciativa das editoras ou por própria iniciativa. Trata-se de um trabalho que envolve o estabelecimento de objetivo da coleção didática, "concepção de língua e de aprendizagem, conteúdo e atividades coerentes com a proposta e com o público alvo a ser atingido" (SILVA, 2017, p. 139). Para tanto, ocorre um processo de avaliação tomando por base critérios dispostos em um edital que rege a edição do programa ${ }^{2}$. As avaliações desenvolvidas nesse processo geram a produção de Resenhas dos livros aprovados, que deverão compor o Guia de Livros Didáticos, o

1 "O Programa Nacional do Livro e do Material Didático (PNLD) compreende um conjunto de ações voltadas para a distribuição de obras didáticas, pedagógicas e literárias, entre outros materiais de apoio à prática educativa, destinados aos alunos e professores das escolas públicas de educação básica do País. O PNLD também contempla as instituições comunitárias, confessionais ou filantrópicas sem fins lucrativos e conveniadas com o Poder Público. As escolas participantes do PNLD recebem materiais de forma sistemática, regular e gratuita. Trata-se, portanto, de um Programa abrangente, constituindo-se em um dos principais instrumentos de apoio ao processo de ensino-aprendizagem nas Escolas beneficiadas." Disponível em: http://www. fnde.gov.br/programas/livro-didatico/livro-didatico-funcionamento; Acesso em 16/02/2020.

2 Critérios disponíveis em: http://www.fnde.gov.br/programas/livro-didatico/livro-didaticofuncionamento; Acesso em 26/01/2020.

TOGNATO, M. I. R., BUTTLER, D. B. Resenhas dos livros didáticos aprovados pelo Guia do PNLD/2020 de língua portuguesa: uma ferramenta para 0 trabalho docente 
que atribui ao avaliador uma responsabilidade social pela chegada do livro didático ao aluno das escolas públicas, para que o professor possa fazer a escolha dos livros aprovados de modo mais apropriado (SILVA, 2017).

Por essas razões, optamos por analisar as Resenhas dos livros didáticos aprovados pelo PNLD 2020, apresentados no Guia de Língua Portuguesa, no sentido de investigar e elucidar os aspectos que podem contribuir para a avaliação e a escolha que o professor deve fazer, pelo modo como são apresentados nas Resenhas. Pois, a descrição e os argumentos, apresentados a respeito de cada livro, podem motivar ou influenciar a tomada de decisão sobre a escolha a ser feita a partir de critérios que possam fazer a diferença no que tange a possíveis contribuições aos saberes e Capacidades Docentes necessários ao ensino de línguas. Em outras palavras, os livros didáticos aprovados deveriam corresponder ou atender às necessidades tanto de ensino quanto de aprendizagem. Entretanto, há que se considerar que o PNLD envolve a esfera nacional, o que pode contribuir para um distanciamento das especificidades de cada estado, região, município ou escola, pois sua função assume importância diferenciada de acordo com as condições, lugares e situações em que é utilizado nos diferentes âmbitos escolares. Por isso, também, nos preocupamos em olhar para as Resenhas que apresentam as características dos livros aprovados pelo PNLD 2020, uma vez que estão relacionadas com o documento da BNCC (Base Nacional Comum Curricular) ${ }^{3}$, que prima por uma orientação mais ampla a nível nacional.

Para tanto, fundamentamos nosso estudo nos aportes teórico-metodológicos do Interacionismo Sociodiscursivo (ISD) (BRONCKART, [1997]2009), das Capacidades de Linguagem (CL) (DOLZ; PASQUIER; BRONCKART, 1993; CRISTOVÃO ET. AL., 2010; CRISTOVÃO; STUTZ, 2011) e dos Saberes e Capacidades Docentes (HOFSTETTER; SCHNEUWLY, 2009; STUTZ, 2012). Partindo de tais princípios, guiamos nosso estudo pelos seguintes questionamentos:

Quais aspectos apontados pelas características dos livros didáticos apresentados nas Resenhas do Guia do PNLD 2020 favorecem a mobilização e a articulação

3 A BNCC (Base. Nacional Curricular Comum) e o Guia do livro didático são documentos que orientam a prática do profissional de línguas, tanto em relação ao conteúdo a ser ensinado e à habilidade a ser desenvolvida, quanto ao instrumento a ser utilizado.

TOGNATO, M. I. R., BUTTLER, D. B. Resenhas dos livros didáticos aprovados pelo Guia do PNLD/2020 de língua portuguesa: uma ferramenta para o trabalho docente 
Linha D’Água (Online), São Paulo, v. 33, n. 2, p. 189-214, maio-ago. 2020

entre as Capacidades de Linguagem, os saberes e as Capacidades Docentes necessários ao ensino de Língua Portuguesa?

Quais as possíveis limitações e contribuições das informações apresentadas pelas Resenhas para a escolha do livro didático pelo professor e para o ensino de Língua Portuguesa?

Para tratar do tema proposto em nossa discussão, este artigo organiza-se pelas partes, após esta introdução, a saber: os aportes norteadores deste estudo, os procedimentos metodológicos utilizados, a discussão dos resultados obtidos e, por fim, as considerações finais sobre as possíveis contribuições e limitações do trabalho realizado.

\section{A perspectiva interacionista sociodiscursiva, as capacidades de lingua- gem e o saberes docentes necessários ao ensino de línguas}

Partindo da perspectiva interacionista sociodiscursiva (BRONCKART, [1997] 2009), que considera a linguagem como elemento central ao desenvolvimento humano, tomamos a linguagem como ponto de partida para uma proposta de discussão acerca do que os livros didáticos aprovados pelo PNLD 2020 podem oferecer ao ensino de Língua Portuguesa. Trata-se de uma oportunidade de analisarmos a descrição desses materiais, pelo que o Guia PNLD 2020 nos oferece, com o intuito de investigar a proposta do trabalho com a linguagem, de modo a contribuir para a formação e o desenvolvimento de nossos alunos, a fim de que tenham condições de, pela linguagem, interagir no mundo; bem como se os saberes e Capacidades Cocentes necessários ao ensino são contemplados.

Nesse sentido, em se tratando das Capacidades de Linguagem, tomamos por base os estudos de Dolz, Pasquier e Bronckart (1993), Schneuwly e Dolz (2004), Stutz e Cristovão (2011) e Cristovão (2013). Primeiramente, foram apontadas as Capacidades de Ação, Discursivas e Linguístico-Discursivas. As Capacidades de Ação (CA) envolvem elementos contextuais da situação de comunicação, tais como: emissor e receptor do texto, local e período da produção, posição social ocupada pelo emissor e receptor, função social e objetivo do texto. As Capacidades 
Linha D'Água (Online), São Paulo, v. 33, n. 2, p. 189-214, maio-ago. 2020

Discursivas referem-se ao plano global do texto, à organização e à progressão textual, abrangendo o início, o desenvolvimento e a finalização do texto, tipos de discurso, sequências linguísticas ou textuais, o conteúdo temático, o tipo ou conjunto de informações que aparecem no texto, além do uso de conectivos e operadores argumentativos. As Capacidades Linguístico-Discursivas (CLD) são constituídas de operações de textualização envolvendo conexão e coesão nominal e verbal, mecanismos enunciativos de gerenciamento de vozes e modalização, oração e período, aspectos léxico-gramaticais como escolha lexical, referências pronominais, dentre outros (SCHNEUWLY; DOLZ, 2004; STUTZ; CRISTOVÃO, 2011; TOGNATO; OLIVEIRA, 2018; FOGAÇA; TOGNATO; MIQUELANTE, 2020; PINTO; TOGNATO; MIQUELANTE, 2020).

Em um momento posterior, Stutz e Cristovão (2011) e Cristovão (2013) propuseram as Capacidades de Significação (CS) no sentido de ampliar as Capacidades anteriores. As CS referem-se às questões contextuais e críticas mais amplas, envolvendo construção de sentido a partir de conhecimentos relacionados às práticas sociais inseridas em "esferas de atividade, atividades de linguagem e praxiológicas” (STUTZ; CRISTOVÃO, 2011, p. 576) remetendo a contextos ideológicos, históricos, sócio-culturais, econômicos, dentre outros (TOGNATO; OLIVEIRA, 2018). Em outras palavras, as CS envolvem a "compreensão da relação entre textos e a forma de ser, pensar, agir e sentir de quem o produz e de quem o recebe, construção de mapas semânticos [...] construção de conjuntos de pré-construídos coletivos, capacidade de relacionar os aspectos macro com sua realidade", bem como sobre as "capacidades de posicionar-se sobre as relações textos-contextos"(STUTZ; CRISTOVÃO, 2011, p. 576). Ademais, tais Capacidades de Linguagem foram desdobradas em critérios a fim de contribuir para uma compreensão mais ampliada acerca de suas funções no ensino de línguas. Tais critérios foram propostos por Cristovão et al. (2010), Stutz e Cristovão (2011) e Lanferdini e Cristovão (2011), sendo revistos em Miquelante (2019).

Diante disso, consideramos as CL fundamentais para o trabalho com a compreensão e produção de textos, sejam orais ou escritos, uma vez que podem auxiliar o aluno na construção dos usos da língua e da linguagem, a fim de que possa interagir com o mundo em diferentes situações de comunicação. Assim, corroboramos 
Linha D'Água (Online), São Paulo, v. 33, n. 2, p. 189-214, maio-ago. 2020

com Fogaça, Tognato e Miquelante (2020), ao destacarem o movimento de imbricação entre as CL, conforme ilustra a Figura 1.

Figura 1: Movimento das capacidades de linguagem

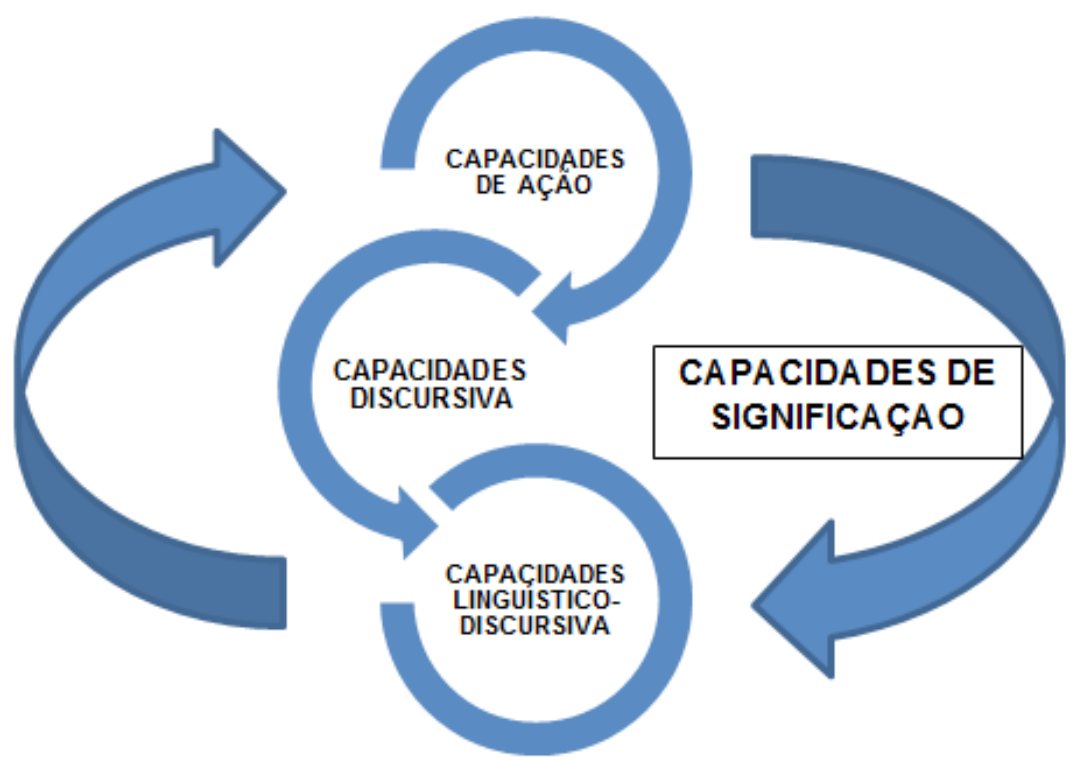

Fonte: Fogaça, Tognato e Miquelante (2020, p. 396), com base em Schneuly e Dolz (2004), Stutz e Cristovão (2011) e Cristovão (2013).

Como as autoras ressaltam, a mobilização de tais CL "são imbricadas no interior das atividades propostas" (FOGAÇA; TOGNATO; MIQUELANTE, 2020, p. 396), e sua integração pode contribuir para um processo de aprendizagem mais efetivo, embora possa haver dificuldades e percalços por esse caminho.

No que concerne aos saberes, pautamos nossos estudos em Stutz (2012), que aborda os saberes a ensinar e para ensinar, tomando por base os estudos da área da Didática das Línguas da Escola de Genebra (HOFSTETTER; SCHNEUWLY, 2009; GAGNON; SURIAN, 2011). Os saberes a ensinar dizem respeito à dimensão dos conteúdos a serem ensinados e aprendidos, enquanto que os saberes para ensinar envolvem os aspectos da dimensão metodológica ou didático-pedagógica (TOGNATO; OLIVEIRA, 2018). Podemos constatar essa discussão e a preocupação com tais questões na área da Educação no Brasil nos estudos de Libâneo (2015), ao tratar dos conhecimentos necessários à docência, que seriam os conhecimentos disciplinar e pedagógico. A nosso ver, é possível estabelecer uma

TOGNATO, M. I. R., BUTTLER, D. B. Resenhas dos livros didáticos aprovados pelo Guia do PNLD/2020 de língua portuguesa: uma ferramenta para o trabalho docente 
Linha D’Água (Online), São Paulo, v. 33, n. 2, p. 189-214, maio-ago. 2020

correlação entre os conceitos abordados pela Escola de Genebra e os conceitos apresentados pro Libâneo no Brasil, uma vez que os saberes a ensinar parecem estar para o conhecimento disciplinar assim como os saberes para ensinar parecem estar para o conhecimento pedagógico, conforme ilustramos na Figura 2.

Figura 2: Correlação entre os saberes docentes da Escola de Genebra e os conhecimentos da Educação no Brasil

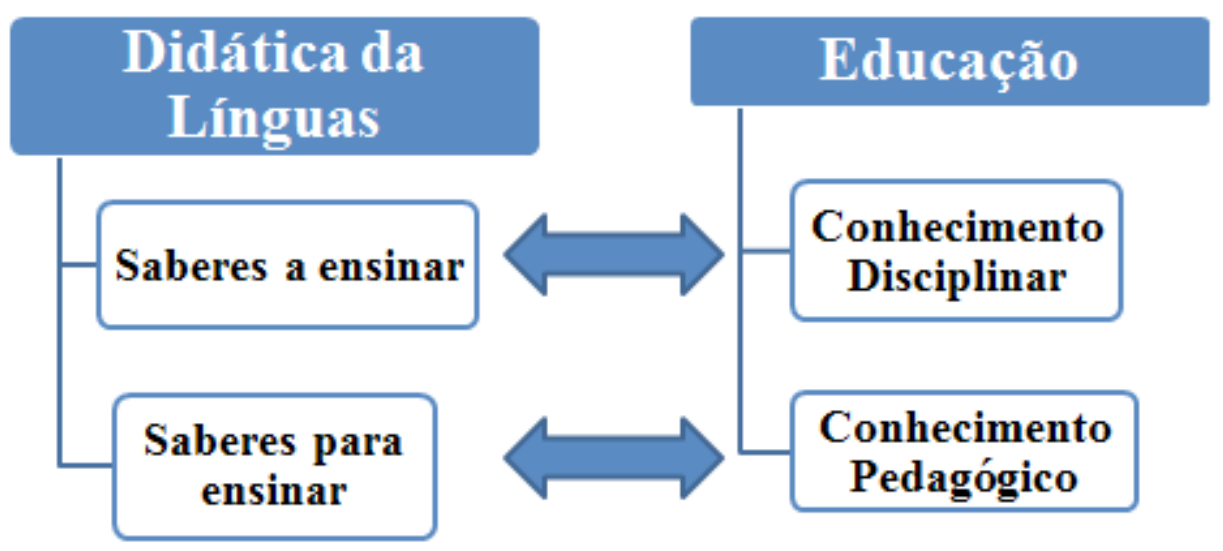

Fonte: (HOFSTETTER; SCHNEUWLY, 2009; LIBÂNEO, 2015).

Quanto aos saberes a ensinar, além de identificar nas Resenhas os conteúdos e as CL a serem mobilizados pelos livros didáticos, consideramos as práticas de linguagem a serem tratadas nos livros, de acordo com os eixos propostos pelo documento da BNCC, a saber: Leitura, Produção de textos, Oralidade e Análise Linguística/Semiótica, conforme o Quadro 1.

TOGNATO, M. I. R., BUTTLER, D. B. Resenhas dos livros didáticos aprovados pelo Guia do PNLD/2020 de língua portuguesa: uma ferramenta para o trabalho docente 
Linha D'Água (Online), São Paulo, v. 33, n. 2, p. 189-214, maio-ago. 2020

Quadro 1: Eixos/práticas de linguagem propostos pela BNCC

\begin{tabular}{|l|l|}
\hline $\begin{array}{l}\text { EIXOS/PRÁTICAS } \\
\text { DE LINGUAGEM }\end{array}$ & \multicolumn{1}{c|}{ DESCRIÇÃO } \\
\hline Oralidade & $\begin{array}{l}\text { Aprofundam-se o conhecimento e o uso da língua oral, as carac- } \\
\text { terísticas de interações discursivas e as estratégias de fala e escuta } \\
\text { em intercâmbios orais. }\end{array}$ \\
\hline $\begin{array}{l}\text { Análise Linguística/ } \\
\text { Semiótica }\end{array}$ & $\begin{array}{l}\text { Sistematiza-se a alfabetização, particularmente nos dois primeiros } \\
\text { anos, e desenvolvem-se, ao longo dos três anos seguintes, a obser- } \\
\text { vação das regularidades e a análise do funcionamento da língua e } \\
\text { de outras linguagens e seus efeitos nos discursos. }\end{array}$ \\
\hline Leitura/Escuta & $\begin{array}{l}\text { Amplia-se o letramento, por meio da progressiva incorporação de } \\
\text { estratégias de leitura em textos de nível de complexidade crescen- } \\
\text { te. }\end{array}$ \\
\hline Produção de Textos & $\begin{array}{l}\text { Desenvolve-se progressiva incorporação de estratégias de produ- } \\
\text { ção de textos de diferentes gêneros textuais. }\end{array}$ \\
\hline
\end{tabular}

Fonte: BRASIL. Base Nacional Comum Curricular: Educação Infantil e Ensino Fundamental (2017, p. 89).

Além disso, ainda no que tange aos saberes a ensinar, a BNCC apresenta as competências relacionadas ao que se espera que o aluno seja capaz de fazer ao estudar a Língua Portuguesa no Ensino Fundamental. Como tais competências estão vinculadas aos conteúdos a serem ensinados e aprendidos, ou seja, aos saberes a ensinar e, além disso, algumas das Resenhas sobre os livros didáticos aprovados apresentam uma referência aos princípios e orientações da BNCC, apresentamos tais competências no Quadro 2.

TOGNATO, M. I. R., BUTTLER, D. B. Resenhas dos livros didáticos aprovados pelo Guia do PNLD/2020 de língua portuguesa: uma ferramenta para 0 trabalho docente 


\section{Linha D'Água (Online), São Paulo, v. 33, n. 2, p. 189-214, maio-ago. 2020}

Quadro 2: Competências específicas de Língua Portuguesa para o ensino fundamental

1. Compreender a língua como fenômeno cultural, histórico, social, variável, heterogêneo e sensível aos contextos de uso, reconhecendo-a como meio de construção de identidades de seus usuários e da comunidade a que pertencem.

2. Apropriar-se da linguagem escrita, reconhecendo-a como forma de interação nos diferentes campos de atuação da vida social e utilizando-a para ampliar suas possibilidades de participar da cultura letrada, de construir conhecimentos (inclusive escolares) e de se envolver com maior autonomia e protagonismo na vida social.

3. Ler, escutar e produzir textos orais, escritos e multissemióticos que circulam em diferentes campos de atuação e mídias, com compreensão, autonomia, fluência e criticidade, de modo a se expressar e partilhar informações, experiências, ideias e sentimentos, e continuar aprendendo.

4. Compreender o fenômeno da variação linguística, demonstrando atitude respeitosa diante de variedades linguísticas e rejeitando preconceitos linguísticos.

5. Empregar, nas interações sociais, a variedade e o estilo de linguagem adequados à situação comunicativa, ao(s) interlocutor(es) e ao gênero do discurso/gênero textual.

6. Analisar informações, argumentos e opiniões manifestados em interações sociais e nos meios de comunicação, posicionando-se ética e criticamente em relação a conteúdos discriminatórios que ferem direitos humanos e ambientais.

7. Reconhecer o texto como lugar de manifestação e negociação de sentidos, valores e ideologias.

8. Selecionar textos e livros para leitura integral, de acordo com objetivos, interesses e projetos pessoais (estudo, formação pessoal, entretenimento, pesquisa, trabalho etc.).

9. Envolver-se em práticas de leitura literária que possibilitem o desenvolvimento do senso estético para fruição, valorizando a literatura e outras manifestações artístico-culturais como formas de acesso às dimensões lúdicas, de imaginário e encantamento, reconhecendo o potencial transformador e humanizador da experiência com a literatura.

10. Mobilizar práticas da cultura digital, diferentes linguagens, mídias e ferramentas digitais para expandir as formas de produzir sentidos (nos processos de compreensão e produção), aprender e refletir sobre o mundo e realizar diferentes projetos autorais.

Fonte: BRASIL. Base Nacional Comum Curricular: Educação Infantil e Ensino Fundamental (2017, p. 87). 
Diante do exposto, podemos perceber que a proposta de trabalho para o ensino de Língua Portuguesa da BNCC pode ser relacionada ao desenvolvimento das Capacidades de Linguagem, visto que envolve o entendimento do uso da linguagem e seus "contextos de uso", a linguagem considerada "forma de interação" em "diferentes campos de atuação da vida social", o emprego, nas interações sociais, da variedade e do estilo de linguagem "adequados à situação comunicativa, ao(s) interlocutor(es) e ao gênero do discurso/gênero textual", o reconhecimento do texto "como lugar de manifestação e negociação de sentidos, valores e ideologias", dentre outros aspectos já mencionados.

No tocante aos dois materiais usados pelos professores, tanto o livro didático quanto a BNCC, Buttler (2014) corrobora que a linguagem é um elemento essencial na construção da ação e da significação, na negociação, nas tomadas de decisão, no planejamento, pois há discursos nessas relações, já que o docente sempre está se expressando e produzindo textos.

No que concerne aos saberes para ensinar, mais especificamente, às Capacidades Docentes, corroboramos com Stutz (2012, p. 79), ao defender que,

As capacidades docentes são uma alternativa para guiar o trabalho de formação inicial de professores de LE, visto que elas trazem especificidades sobre os saberes que precisam ser transformados com o intuito de conscientizar, de construir ou modificar operações psíquicas. Compreendemos que as transformações dos saberes ocorrem em função da construção de capacidades docentes (STUTZ, 2012, p. 79).

A autora defende o trabalho com as Capacidades Docentes no contexto de formação inicial de professores de línguas, no entanto, destacamos aqui a importância de tais Capacidades também para o contexto de formação continuada, em função da relevância que essas têm para o trabalho do professor no processo de ensino e aprendizagem de línguas, uma vez que o professor precisa estar atento, o tempo todo, às suas atribuições, ao que precisa realizar e desenvolver, enfim, ao seu agir docente, para que seus alunos possam aprender a língua, seja materna ou estrangeira, mais efetivamente ou de modo mais preciso. Daí a importância de entendermos o que tais capacidades podem significar e até que ponto podem ser retomadas ou relembradas na descrição e avaliação dos livros didáticos de Língua 
Linha D'Água (Online), São Paulo, v. 33, n. 2, p. 189-214, maio-ago. 2020

Portuguesa aprovados pelo PNLD 2020 e apresentados no Guia PNLD 2020, no sentido de orientar o professor para uma escolha mais adequada do livro didático ao seu contexto de ensino e aprendizagem.

De acordo com Stutz (2012, p. 83), as Capacidades Docentes são “[...] operações psíquicas já existentes e a serem construídas ou aperfeiçoadas tanto em relação ao agir praxiológico quanto ao agir linguageiro". Nessa perspectiva, para a autora, o professor, como protagonista do ato de ensino, pode "aprimorar um rol de aptidões necessárias, isto é, capacidades docentes para o métier do professor”. Em relação ao agir praxiológico, Buttler (2014) reitera que o professor constrói interpretações sobre os textos veiculados nesse métier, e essas construções são refletidas na sua prática.

Assim, tomamos por base o estudo de Stutz (2012), que se pauta no documento "Portfolio européen pour les enseignants en langues en formation initiale" (EUROPA, 2007), bem como os estudos de Cristovão e Machado (2005), ao analisarem as Diretrizes para a Formação Inicial de Professores. Novamente, destacamos a importância de tais capacidades para repensarmos a formação continuada do professor de línguas e ressignificarmos as práticas formativas, no caso deste estudo, em relação ao uso de livro didático no ensino de Língua Portuguesa. Segundo Stutz (2012, p. 82), o documento PEPELF “é referência para o ensino de línguas em 33 países membros do Centro Europeu para as Línguas Modernas" e apresenta sete categorizações de saberes e Capacidades Docentes (EUROPA, 2007, p. 84), a saber: contexto, metodologia, recursos, planificação de aulas, regências de aulas, aprendizagem autônoma e avaliação da aprendizagem, conforme mostra o Quadro 3. Stutz (2012) alinha tais saberes aos conceitos propostos por Hofstetter e Schneuwly (2009), como os saberes a ensinar e para ensinar.

TOGNATO, M. I. R., BUTTLER, D. B. Resenhas dos livros didáticos aprovados pelo Guia do PNLD/2020 de língua portuguesa: uma ferramenta para 0 trabalho docente 
Quadro 3: Os saberes e as capacidades docentes para a formação inicial de professores de línguas

\section{OS SABERES E AS CAPACIDADES DOCENTES PARA O ENSINO DE LÍNGUAS NA FORMAÇÃO INICIAL}

\section{1) CONTEXTO}

Capacidade de compreender/verificar:

(A) as exigências estabelecidas nas prescrições nacionais e locais;

(B) os objetivos e necessidade dos alunos;

(C) o papel do professor de LE:

I. autoavaliação dos alunos-professores;

II. avaliação do ensino de acordo com os princípios teóricos;

III. o suporte da pesquisa;

IV. o aceite do retorno de informações dos alunos-professores, professor regente de turma, professora formadora;

V. avaliação do trabalho dos colegas e contribuição por meio de críticas construtivas;

VI. identificação dos problemas pedagógicos e didáticos dos alunos e do ensino por meio da pesquisa-ação e de estudos de caso;

(D) os recursos e as restrições na instituições de ensino;

2) METODOLOGIA

Capacidade de analisar/avaliar:

(A) a produção oral e a produção escrita dos alunos;

(B) a interação oral e a interação escrita;

(C) a compreensão oral e escrita;

(D) a gramática;

(E) o vocabulário;

(F) a cultura;

3) RECURSOS

Capacidade de:

(A) analisar livros didáticos;

(B) selecionar textos;

(C) produzir atividades;

[continua]

TOGNATO, M. I. R., BUTTLER, D. B. Resenhas dos livros didáticos aprovados pelo Guia do PNLD/2020 de língua portuguesa: uma ferramenta para 0 trabalho docente 
Linha D’Água (Online), São Paulo, v. 33, n. 2, p. 189-214, maio-ago. 2020

[continuação]

\begin{tabular}{|c|}
\hline $\begin{array}{c}\text { OS SABERES E AS CAPACIDADES DOCENTES } \\
\text { PARA O ENSINO DE LÍNGUAS NA FORMAÇÃO INICIAL }\end{array}$ \\
\hline $\begin{array}{l}\text { 4) PLANIFICAÇÃO DAS AULAS } \\
\text { Capacidade de: } \\
\text { (A) identificar os objetivos de aprendizagem; } \\
\text { (B) planificar os conteúdos da aula; } \\
\text { (C) organizar o curso; }\end{array}$ \\
\hline $\begin{array}{l}\text { 5) REGÊNCIA DE AULAS } \\
\text { Capacidade de: } \\
\text { (A) utilizar o plano de aula e do curso; } \\
\text { (B) apresentar um conteúdo linguístico, estabelecer relações com conteúdos locais/interna- } \\
\text { cionais e estabelecer relações entre língua e cultura; } \\
\text { (C) interagir com os alunos durante a aula; } \\
\text { (D) gerenciar a classe; } \\
\text { (E) utilizar a língua alvo; }\end{array}$ \\
\hline $\begin{array}{l}\text { 6) APRENDIZAGEM AUTÔNOMA } \\
\text { Capacidade de: } \\
\text { (A) contribuir para o desenvolvimento da autonomia dos alunos; } \\
\text { (B) inserir tarefas de casa adequadas ao aprendizado dos alunos; } \\
\text { (C) planificar e gerenciar projetos e portfolios; } \\
\text { (D) utilizar ambientes de aprendizagem virtual; } \\
\text { (E) organizar atividades extraclasse (passeios, viagens). }\end{array}$ \\
\hline $\begin{array}{l}\text { 7) AVALIAÇÃO DE APRENDIZAGEM } \\
\text { Capacidade de: } \\
\text { (A) compreender artefatos de avaliação; } \\
\text { (B) reconhecer o desempenho dos alunos; } \\
\text { (C) promover autoavaliação dos alunos; } \\
\text { (D) analisar erros dos alunos. }\end{array}$ \\
\hline
\end{tabular}

Fonte: Stutz (2012, p. 84).

TOGNATO, M. I. R., BUTTLER, D. B. Resenhas dos livros didáticos aprovados pelo Guia do PNLD/2020 de língua portuguesa: uma ferramenta para 0 trabalho docente 
Portanto, nosso intuito é o de investigar se, além das possíveis relações entre as características dos livros didáticos aprovados apresentadas pelas Resenhas do Guia PNLD 2020 e as CL, apontam aspectos relacionados às Capacidades Docentes, conforme indicadas por Stutz (2012) em sua pesquisa, no que tange ao contexto, metodologia e recursos, muito embora as informações sobre os livros didáticos façam referência, de certa forma, à regência de aulas, à aprendizagem autônoma e à avaliação da aprendizagem, com o intuito de contribuir não somente para a tomada de decisão e para a escolha do livro didático, mas também para a ressignificação das práticas pedagógicas e profissionais.

\section{Procedimentos metodológicos}

Ao desenvolver o percurso metodológico, além de buscar estudos já realizados na área relacionados à temática de nossa proposta de discussão, tais como os textos de Bonini e Yano (2018) e de Silva (2017), procuramos identificar os elementos constitutivos do nosso objeto de estudo, que foram as Resenhas dos livros didáticos aprovados pelo PNLD 2020 e seus critérios e/ou elementos constitutivos, os quais podem ser encontrados em seções, a saber: visão geral, descrição da obra, análise da obra e em sala de aula, conforme ilustra o Quadro 3. De acordo com o documento, o objetivo dessas Resenhas é de "apresentar não apenas as estruturas que formam cada coleção, mas também seus conteúdos, princípios, fundamentos teóricos e suas propostas de atividades e avaliações" (BRASIL, 2019, p. 1).

No que concerne à organização e sistematização das Resenhas, primeiramente, apresentam informações sobre os aspectos, a saber: título, autoria, código do livro, editorial, tema(s), categoria (Ensino Fundamental - Anos Finais), gênero, título do volume, número de páginas, ano da edição (2018), número da edição e a indicação de recurso áudio visual e material digital (BRASIL, 2019).

$\mathrm{Na}$ sequência, as Resenhas apresentam cinco seções que evidenciam a finalidade de descrever os livros didáticos de Língua Portuguesa aprovados pelo PNLD 2020, a partir de sua visão geral, da descrição e análise da obra, bem como dos aspectos referentes ao trabalho em sala de aula. Tais aspectos e suas finalidades podem ser visualizados conforme ilustra o Quadro 4. 
Linha D’Água (Online), São Paulo, v. 33, n. 2, p. 189-214, maio-ago. 2020

Quadro 4: Aspectos descritos nas resenhas das obras aprovadas pelo PNLD 2020

\begin{tabular}{|c|l|}
\hline SEÇÕES & \multicolumn{1}{|c|}{$\begin{array}{c}\text { FINALIDADE DOS ASPECTOS DE DESCRIÇÃO DOS LD } \\
\text { APROVADOS PELO PNLD 2020 }\end{array}$} \\
\hline Visão Geral & $\begin{array}{l}\text { Apresenta as características gerais da obra, os propósitos, os referenciais teó- } \\
\text { rico-metodológicos, os conceitos centrais, a abordagem didático-pedagógica } \\
\text { e a organização do Manual do Professor e do Manual do Professor Digital, } \\
\text { para que você tenha a visão inicial dos livros da coleção e dos pressupostos } \\
\text { presentes em todos os volumes que a formam. }\end{array}$ \\
\hline $\begin{array}{c}\text { Descrição da } \\
\text { Obra }\end{array}$ & $\begin{array}{l}\text { Descreve, de forma detalhada, a estrutura e a organização dos volumes (nú- } \\
\text { mero de páginas, capítulos, temas, conteúdos), as relações entre estes e ou- } \\
\text { tras informações relevantes da coleção. }\end{array}$ \\
\hline Onálise da & $\begin{array}{l}\text { Aponta as qualidades, ressalvas, o arranjo das competências e habilidades da } \\
\text { Base Nacional Comum Curricular (BNCC), a formação cidadã, o respeito à } \\
\text { legislação, às diretrizes educacionais, a qualidade do projeto gráfico, ou seja, } \\
\text { delineia a proposta pedagógica da obra em sua totalidade: Livro do Estudante, } \\
\text { Manual do Professor e o Manual do Professor Digital. }\end{array}$ \\
\hline Em Sala de & $\begin{array}{l}\text { Indica, de forma mais explícita, como a coleção se vincula ao cotidiano do } \\
\text { espaço escolar. Aponta suas potencialidades pedagógicas e seus limites, onde } \\
\text { você, professor(a), deve atuar mais intensamente, complementando detalhes } \\
\text { para além dos livros e das páginas escritas que chegam até os(as) estudantes. }\end{array}$ \\
\hline
\end{tabular}

Fonte: Guia PNLD 2020 (BRASIL, 2019, p. 1-2). Disponível em: https://pnld.nees.com.br/ assets-pnld/guias/Guia_pnld_2020_pnld2020-lingua-portuguesa.pdf; Acesso em 26/01/2020.

Diante do exposto, notamos que os aspectos acima, em suas finalidades, abrangem tanto os saberes a ensinar quanto para ensinar. Contudo, realizamos a análise das Resenhas a fim de constatar até que ponto tais saberes aparecem na descrição dos livros didáticos aprovados.

Após identificar os aspectos que descreveriam os livros didáticos aprovados pelo PNLD 2020 em Resenhas e entender suas finalidades, analisamos as Resenhas desses livros, com o objetivo de reconhecer as possíveis relações com as CL, bem como com os saberes e Capacidades Docentes.

O tratamento dos dados ocorreu com base nos temas evocados nas seções das Resenhas, por meio da busca de palavras-chave que pudessem remeter ou estar relacionadas tanto às CL quanto aos saberes e Capacidades Docentes mencionados neste trabalho.

TOGNATO, M. I. R., BUTTLER, D. B. Resenhas dos livros didáticos aprovados pelo Guia do PNLD/2020 de língua portuguesa: uma ferramenta para 0 trabalho docente 
Linha D'Água (Online), São Paulo, v. 33, n. 2, p. 189-214, maio-ago. 2020

\section{Análise em discussão: possíveis contribuições e limitações das resenhas dos livros didáticos apresentadas no Guia PNLD 2020}

No que concerne às análises das Resenhas dos livros didáticos apresentadas no Guia PNLD 2020, procuramos identificar suas possíveis contribuições e limitações para o ensino de Língua Portuguesa no Ensino Fundamental das escolas públicas do Brasil, por meio de uma análise comparativa entre as seis Resenhas mencionadas, no sentido de reconhecer a possibilidade de mobilização das CL, bem como de articulação entre os saberes e as Capacidades Docentes necessárias ao ensino de língua portuguesa.

Nesse sentido, primeiramente, obtivemos uma visão do conjunto dos livros aprovados pelo PNLD 2020, conforme ilustram a Figura 3.

Figura 3: Livros didáticos de Língua Portuguesa aprovados pelo PNLD 2020

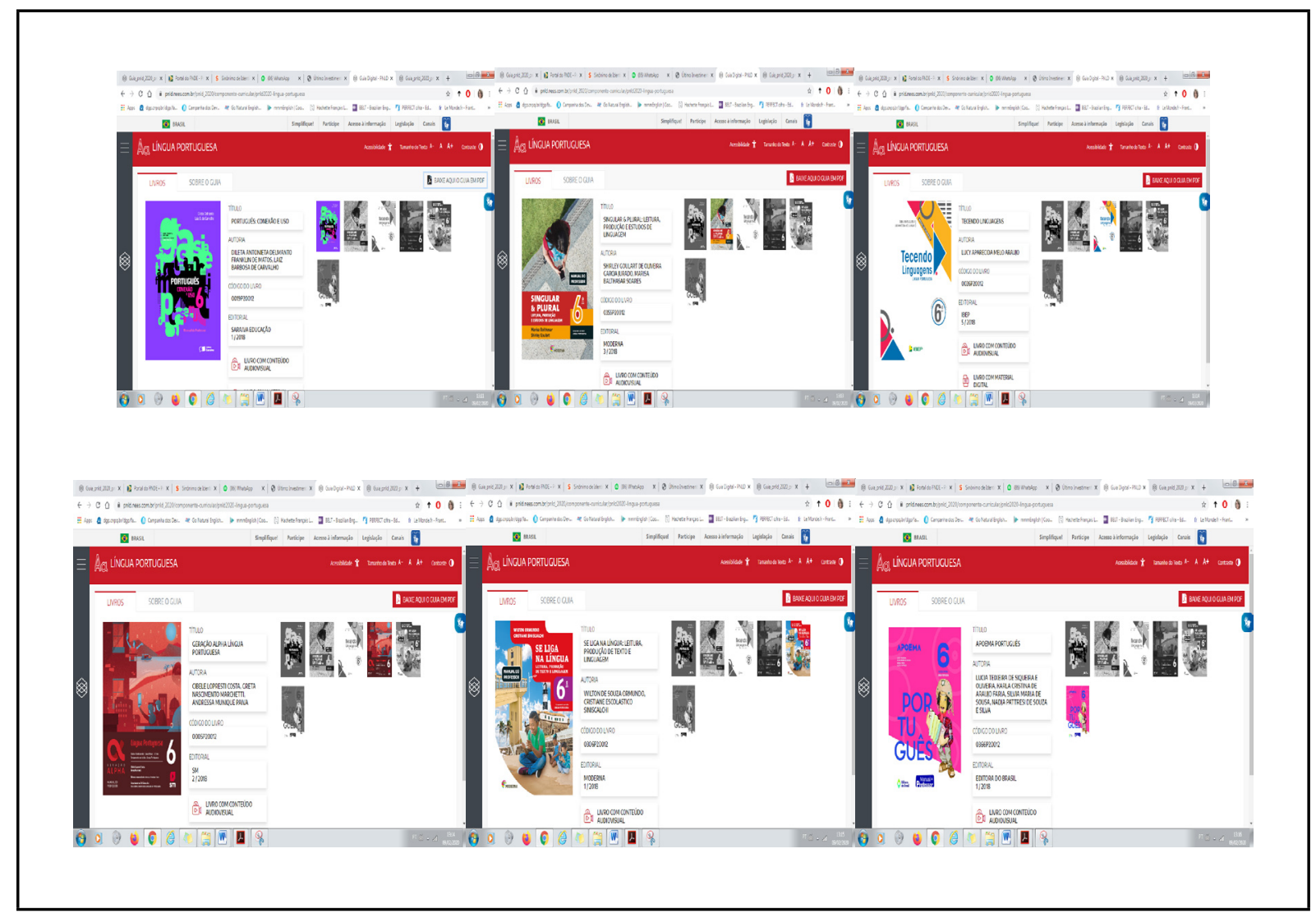

Fonte: Guia PNLD 2020 (BRASIL, 2019), disponível em: https://pnld.nees.com.br/ pnld_2020/componente-curricular/pnld2020-lingua-portuguesa; Acesso em 26/01/2020.

TOGNATO, M. I. R., BUTTLER, D. B. Resenhas dos livros didáticos aprovados pelo Guia do PNLD/2020 de língua portuguesa: uma ferramenta para o trabalho docente 
Linha D'Água (Online), São Paulo, v. 33, n. 2, p. 189-214, maio-ago. 2020

Para a discussão dos resultados das análises de nosso estudo neste texto, em função de espaço, nos limitaremos aos resultados das análises das Resenhas dos seguintes livros didáticos: Apoema Português e Geração Alpha Lingua Portuguesa.

Assim, em relação aos temas evocados na descrição dos livros didáticos de Língua Portuguesa apresentados no Guia PNLD 2020, apontados nas Resenhas, no que diz respeito às CL, identificamos os seguintes dados, conforme mostra o Quadro 5. 
Quadro 5: Temas evocados na descrição dos livros didáticos de Língua Portuguesa pelas Resenhas aprovados pelo PNLD 2020 em relação às CL aos saberes a ensinar e para ensinar

\begin{tabular}{|c|c|c|c|c|}
\hline $\begin{array}{l}\text { LIVROS DE } \\
\text { LP DESCRITOS/ } \\
\text { SEÇÕES }\end{array}$ & VISÃO GERAL & DESCRIÇÃO DA OBRA & ANÁLISE DA OBRA & EM SALA DE AULA \\
\hline $\begin{array}{c}\text { LD } 1 \\
\text { APOEMA } \\
\text { PORTUGUÊS }\end{array}$ & $\begin{array}{l}\text { Gênero textual que orienta atividades } \\
\text { Práticas de linguagem de leitura, pro- } \\
\text { dução de textos, oralidade e análise } \\
\text { linguística/semiótica (CS, CA, CD, } \\
\text { CLD) } \\
\text { Proposta didático-metodológica por } \\
\text { meio de atividades, sequências didá- } \\
\text { ticas e projetos pedagógicos }\end{array}$ & $\begin{array}{l}\text { Leitura de gênero textual, conforme } \\
\text { proposta da BNCC } \\
\text { Manual do professor com orienta- } \\
\text { ções aos docentes } \\
\text { Articulação entre as habilidades } \\
\text { linguísticas (ouvir, falar, ler, escrever) } \\
\text { (CS, CA, CD, CLD) } \\
\text { Proposta teórico-metodológica com } \\
\text { base na BNCC e nos princípios } \\
\text { norteadores do interacionismo socio- } \\
\text { discursivo e com as teorias do texto e } \\
\text { do discurso } \\
\text { Articulação teórico-didático-meto- } \\
\text { dológica para um ensino das práticas } \\
\text { de linguagem de forma contextuali- } \\
\text { zada }\end{array}$ & $\begin{array}{l}\text { Proposta didático-pedagógica coe- } \\
\text { rente e aderente às abordagens teóri- } \\
\text { co-metodológicas da coleção } \\
\text { Textos digitais (orais e escritos) } \\
\text { envolvendo contextos socioculturais, } \\
\text { estudo da forma e do conteúdo, } \\
\text { questões linguísticas, epilinguísticas e } \\
\text { metalinguísticas da língua (CS, CA, } \\
\text { CD, CLD) } \\
\text { Textos analisados nas dimensões es- } \\
\text { truturais, enunciativas e linguístico- } \\
\text { discursivas pelo sistema de gêneros, } \\
\text { conforme proposta da BNCC (CS, } \\
\text { CA, CD, CLD) } \\
\text { Ensino de gramática contextualiza- } \\
\text { da, a partir do texto (CS, CA, CD, } \\
\text { CLD) }\end{array}$ & $\begin{array}{l}\text { Formação de leitores críticos, abran- } \\
\text { gendo contexto de produção, atores } \\
\text { sociais envolvidos na interação, mo- } \\
\text { mento histórico e aspectos culturais } \\
\text { subjacentes aos textos lidos (CS, CA, } \\
\text { CD, CLD) } \\
\text { Práticas de escrita de forma situada } \\
\text { envolvendo contexto de produção, in- } \\
\text { tenção comunicativa, o público-alvo, } \\
\text { característica estilísticas, temáticas e } \\
\text { composicionais do gênero em produ- } \\
\text { ção, efeitos de sentido (CS, CA, CD, } \\
\text { CLD) } \\
\text { Oralidade por meio de atividades } \\
\text { significativas para o desenvolvimento } \\
\text { de competências e habilidades com } \\
\text { gêneros variados } \\
\text { Reflexão do professor acerca da } \\
\text { própria prática pedagógica }\end{array}$ \\
\hline
\end{tabular}


[continuação]

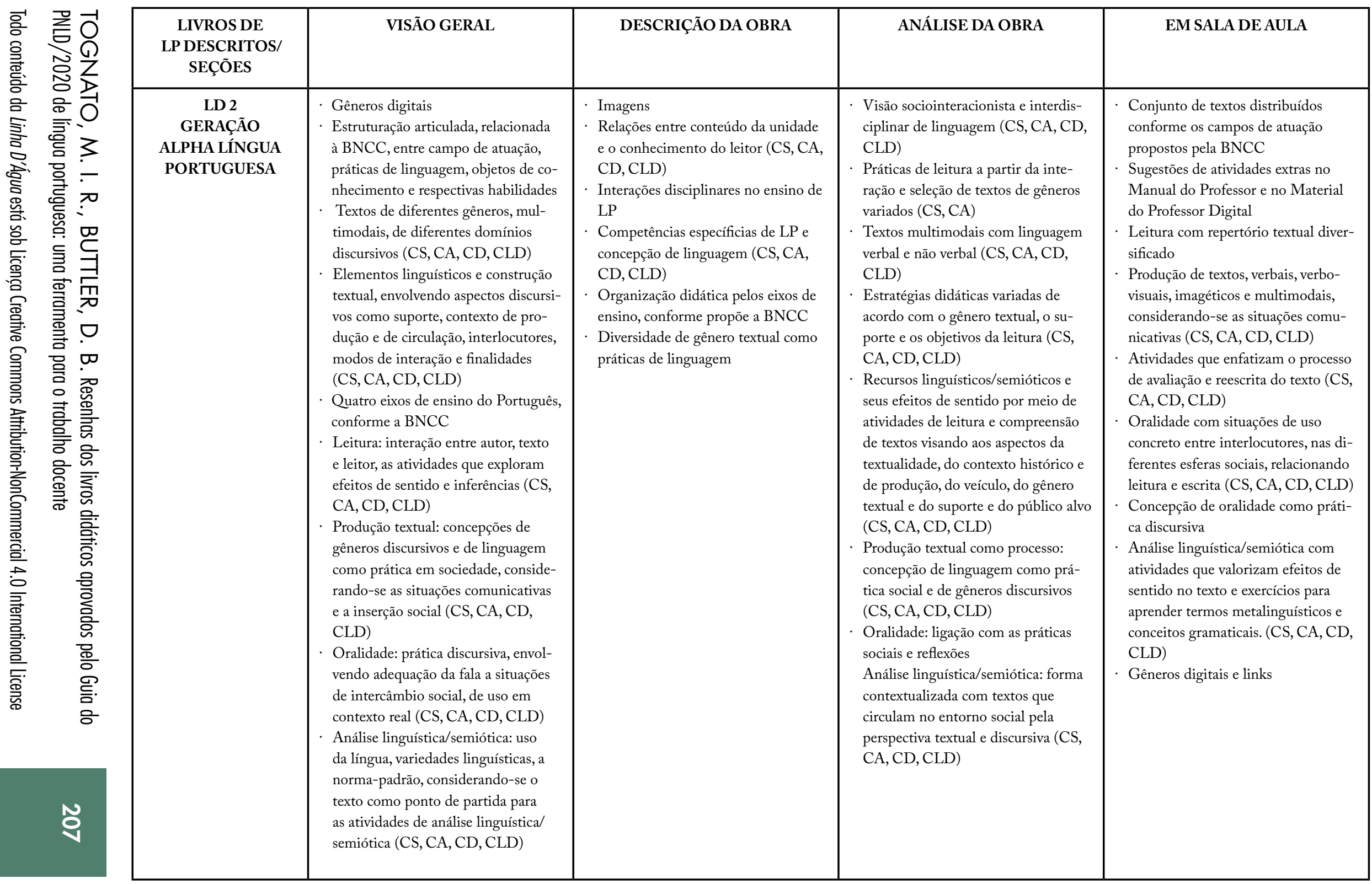

Fonte: As autoras. 
No que tange às CL, constatamos que os livros aprovados fazem referência a um trabalho que pode envolver o desenvolvimento de tais capacidades, por apresentarem conteúdos e procedimentos relacionados à perspectiva interacionista sociodiscursiva, bem como por estabelecerem relações com a proposta para o ensino de línguas, conforme consta na BNCC, que, por sua vez, também propõe um trabalho que possibilita o desenvolvimento das CL.

Em relação aos saberes e às Capacidades Docentes, constatamos algumas possíveis conexões, conforme mostra o Quadro 6.

Quadro 6: Relação entre os LD aprovados e os saberes e as capacidades docentes

\begin{tabular}{|l|l|}
\hline \multicolumn{1}{|c|}{$\begin{array}{c}\text { SABERES DOCENTES } \\
\text { (a ensinar e para ensinar) }\end{array}$} & \multicolumn{1}{|c|}{$\begin{array}{c}\text { CAPACIDADES DOCENTES A PARTIR DO } \\
\text { PEPELF (STUTZ, 2012) }\end{array}$} \\
\hline $\begin{array}{l}\text { - Referência tanto aos con- } \\
\text { teúdos a serem ensinados e } \\
\text { os instrumentos a serem uti- } \\
\text { lizados quanto aos aspectos } \\
\text { metodológicos ou didático } \\
\text {-pedagógicos. }\end{array}$ & $\begin{array}{l}\text { - Referência aos elementos de contexto como a capacidade } \\
\text { de compreender/verificar as exigências estabelecidas nas } \\
\text { prescrições nacionais e locais, os objetivos e necessidades } \\
\text { dos alunos, bem como o papel do professor em relação à } \\
\text { avaliação do ensino de acordo com os princípios teóricos e } \\
\text { à identificação de problemas pedagógicos e didáticos por } \\
\text { meio da reflexão sobre a própria prática pedagógica. }\end{array}$ \\
$\begin{array}{l}\text { - Referência à metodologia pela capacidade de analisar/ } \\
\text { avaliar a produção oral e escrita dos alunos, a interação oral } \\
\text { e escrita, a compreensão oral e escrita, a gramática, o voca- } \\
\text { bulário e os aspectos culturais. } \\
\text { - Referência a recursos envolvendo a capacidade de anali- } \\
\text { sar livros didáticos, selecionar textos e produzir atividades, } \\
\text { se for necessário. } \\
\text { - Referência à avaliação de aprendizagem pela capacidade } \\
\text { de compreender artefatos de avaliação; reconhecer o de- } \\
\text { sempenho dos alunos, promover autoavaliação dos alunos, } \\
\text { bem como analisar seus erros. }\end{array}$ \\
\hline
\end{tabular}

Fonte: As autoras, com base em (HOFSTETTER; SCHNEUWLY, 2009; STUTZ, 2012).

Os dados analisados nos permitiram ver que algumas Resenhas apresentam maiores informações que outras acerca do trabalho com as práticas de linguagem/discursivas, conforme propõe o documento da BNCC, dos conteúdos a serem ensinados e dos aspectos metodológicos que podem orientar o trabalho do 
professor de línguas, o que nos indica a importância de analisarmos o conteúdo das avaliações e descrições das características dos livros didáticos apresentadas no Guia do PNLD 2020, a fim de obtermos maiores e melhores informações sobre os livros a serem escolhidos.

As análises nos possibilitam ver que as avaliações, as descrições, enfim, as características dos livros didáticos apresentadas nas Resenhas no Guia do PNLD 2020, evidenciam possíveis relações com o desenvolvimento das CL, uma vez que fazem referência aos conteúdos e ao trabalho com práticas de linguagem/discursivas (oralidade, análise linguística, leitura/escuta, produção de textos). Além disso, as Resenhas fazem referência à proposta para o ensino de Língua Portuguesa da BNCC, primando pelo uso da linguagem, pelos contextos de uso, interações sociais em diferentes situações de comunicação, interlocutores e gênero do discurso/ gênero textual, conforme já mencionamos neste texto.

Ademais, as análises dos dados nos permitiram entender que, além de ter os saberes e as Capacidades Docentes, o professor de línguas deve também desenvolver, para efetivar sua prática pedagógica e profissional, não somente suas capacidades de selecionar e escolher materiais de um modo geral, mas também suas capacidades de avaliar e de escolher o livro didático dentre outros aprovados pelo PNLD 2020, para que o livro didático escolhido possa corresponder de fato às necessidades de aprendizagem de seus alunos. Para isso, é necessário que haja uma tomada de consciência acerca da importância de se atentar a essas capacidades no momento de avaliação e de escolha do livro didático, pois, de outro modo, os alunos e até mesmo o professor sentirão as consequências de uma escolha inapropriada à sua realidade educacional. Daí a importância desta nossa proposta de discussão de colocar em relevância as Resenhas dos livros didáticos de Língua Portuguesa apresentadas no Guia do PNLD 2020 ao analisá-las.

Por essas razões, defendemos a importância e a necessidade de se estudar e analisar o Guia do PNLD em contextos de formação docente inicial de professores de línguas, a fim de antecipar aos professores em formação os aspectos e critérios para os quais devem estar atentos ao ter que avaliar e escolher livros didáticos em suas futuras situações de trabalho. Pois, a nosso ver, deve haver uma antecipação da compreensão do agir docente e das atribuições do professor de 
Linha D'Água (Online), São Paulo, v. 33, n. 2, p. 189-214, maio-ago. 2020

línguas na formação inicial, de modo que o professor possa sair desse contexto melhor preparado para situações como essa de escolha de livro didático aprovado pelo PNLD, por meio de suas características apresentadas em Resenhas no Guia do PNLD. Daí porque consideramos as Resenhas dos livros didáticos aprovados pelo PNLD apresentadas no Guia ferramentas para o trabalho docente.

\section{Conclusão}

No sentido de responder aos questionamentos apresentados na introdução deste trabalho, nos remetemos a eles para finalizar esta proposta de discussão, considerada, por nós, um debate social inicial sobre o Guia PNLD 2020, mais especificamente, sobre as Resenhas que descrevem e avaliam os livros didáticos de Língua Portuguesa aprovados.

Assim, no que diz respeito ao primeiro questionamento acerca dos aspectos apontados pelas características dos livros didáticos aprovados nas Resenhas no Guia do PNLD 2020 que favorecem a mobilização e a articulação entre as Capacidades de Linguagem, os saberes e Capacidades Docentes necessários ao ensino de Língua Portuguesa, constatamos que os conteúdos das Resenhas apontam para a possibilidade de se trabalhar o desenvolvimento das CL, considerando as práticas de linguagem/discursivas, em relação aos eixos propostos pelo documento da BNCC. Além disso, os conteúdos das Resenhas remetem aos saberes e Capacidades Docentes para os quais o professor de Língua Portuguesa deve se atentar ao avaliar e escolher o livro didático aprovado pelo PNLD 2020. Cabe ao professor, portanto, identificar o quanto e como as Resenhas apresentam as características dos livros didáticos a serem selecionados, bem como as informações necessárias para sua escolha. Daí a importância de trabalharmos os conteúdos dessas Resenhas em contextos de formação docente inicial e continuada.

Em relação ao segundo questionamento, referente às possíveis limitações e contribuições das informações apresentadas pelas Resenhas para a escolha do livro didático pelo professor e para o ensino de Língua Portuguesa, quanto às limitações, algumas Resenhas apontam uma possível lacuna, ao apresentar características de atividades relacionadas especificamente à gramática, indicando-as como sendo 
tradicionais, ao desconsiderarem o texto e o contexto de produção. No que se refere às possíveis contribuições, concluímos que as Resenhas dos livros didáticos aprovados pelo PNLD 2020 apresentadas no Guia do PNLD oferecem informações valiosas para que o professor possa analisar, avaliar e selecionar o livro didático de modo mais efetivo, possibilitando uma escolha mais precisa. No entanto, há que se considerar a necessidade de se estudar e analisar o conteúdo das Resenhas em comparação com os livros didáticos, de modo a se fazer uma escolha mais precisa. Outra contribuição é o fato de que notamos nas resenhas que os campos de atuação ganham destaque nas obras e levam em conta os campos da vida cotidiana e pública com foco nos textos digitais, nas práticas de estudo e pesquisa e na esfera artístico-literária, bem como nas questões linguísticas e nos gêneros textuais escolares.

Por fim, pensamos que um estudo comparativo entre os conteúdos das Resenhas analisadas e dos livros didáticos aprovados pelo PNLD 2020 poderia ser feito com o intuito de evidenciar uma compreensão mais ampliada tanto em relação ao que as Resenhas apresentam sobre esses materiais quanto sobre o que os próprios livros didáticos apresentam, como se constituem, como são organizados e sistematizados. Com isso, esperamos que nosso estudo tenha contribuído para uma discussão inicial acerca da temática apresentada neste texto e que outros estudos e pesquisas sejam desenvolvidos com vistas à expansão desse debate social acerca dos livros didáticos aprovados pelo PNLD 2020, de modo a contribuir para os contextos de formação docente inicial e continuada.

\section{Referências}

BONINI, A.; YANO, D. de C. Avaliação do livro didático como tema da formação inicial do professor de língua portuguesa. Entrepalavras, Fortaleza, v.8, n.2, p. 323-343, maio/ago. 2018.

BRASIL. Ministério da Educação. PNLD 2018: língua portuguesa - guia de livros didáticos - Ensino Médio/Ministério da Educação - Secretária de Educação Básica - SEB - Fundo Nacional de Desenvolvimento da Educação. Brasília, DF: Ministério da Educação, Secretaria de Educação Básica, 2017.

TOGNATO, M. I. R., BUTTLER, D. B. Resenhas dos livros didáticos aprovados pelo Guia do PNLD/2020 de língua portuguesa: uma ferramenta para o trabalho docente 
Linha D'Água (Online), São Paulo, v. 33, n. 2, p. 189-214, maio-ago. 2020

PNLD 2020: língua portuguesa - guia de livros didáticos - Ensino Médio/Ministério da Educação - Secretária de Educação Básica - SEB - Fundo Nacional de Desenvolvimento da Educação. Brasília, DF: Ministério da Educação, Secretaria de Educação Básica, 2019.

BRASIL. Base Nacional Comum Curricular: Educação Infantil e Ensino Fundamental. Brasília: MEC/Secretaria de Educação Básica, 2017.

. Base Nacional Comum Curricular: Ensino Médio. Brasília: MEC/Secretaria de Educação Básica, 2018.

BRONCKART, J-P. Atividade de linguagem, textos e discursos: por um interacionismo sócio-discursivo. Trad. Anna Rachel Machado e Pericles Cunha. São Paulo: EDUC, [1997] 2009.

BUTTLER, D.B. Professor: uma imagem esfacelada? Embu-Guaçu: Lumen et Virtus, 2014.

CRISTOVÃO, V. L. L. Para uma expansão do conceito de capacidades de linguagem. In: BUENO, L.; LOPES, M. A. P. T.; CRISTOVÃO, V. L. (Orgs.). Gêneros Textuais e Formação Inicial: uma homenagem à Malu Matêncio. 1.ed. Campinas: Mercado das Letras, 2013, p. 357-380.

CRISTOVÃO, V. L. L.; MACHADO, A. R. Formação de professores de língua estrangeira: ação política e reflexiva. In: GIMENEZ, T.; JORDÃO, C. M.; ANDREOTTI, V. (Orgs.) Perspectivas educacionais e o ensino de inglês na escola pública. Pelotas: EDUCAT, 2005.

CRISTOVÃO, V. L. L.; BEATO-CANATO, A. P.; FERRARINI, M. A.; PETRECHE, C. R. C.; ANJOS-SANTOS, L. M. Uma proposta de planejamento de ensino de língua inglesa em torno de gêneros textuais. Letras, Santa Maria, v.20, n.40, p. 191-215. jan./jun. 2010.

CRISTOVÃO, V. L. L.; STUTZ, L. Sequências didáticas: semelhanças e especificidades no contexto francófono como L1 e no contexto brasileiro como LE. In: SZUNDY,P.T. C.; ARAÚJO, J. C.; NICOLAIDES, C.; SILVA, K. A. (Orgs.) Linguística Aplicada e sociedade: ensino e aprendizagem de línguas no contexto brasileiro. Campinas: Pontes Editores, 2011, v.1.

DOLZ, J.; PASQUIER, A.; BRONCKART, J.-P. L'acquisition des discours: emergence d'une competence ou apprentissage de capacities langagières diverses? Études de Linguistique appliquée, n.92, p. 23-37, 1993.

EUROPA. CONSEIL DE L'EUROPE. Portfolio européen pour les enseignants em langues em formation initiale. CENTRE EUOPÉEN POUR LES LANGUES VIVANTES (CELV).

TOGNATO, M. I. R., BUTTLER, D. B. Resenhas dos livros didáticos aprovados pelo Guia do PNLD/2020 de língua portuguesa: uma ferramenta para 0 trabalho docente 
Linha D'Água (Online), São Paulo, v. 33, n. 2, p. 189-214, maio-ago. 2020

2007. Disponível em: http://archive.ecml.at/mtp2/publications/C3_Epostl_F_internet.pdf Acesso em: 18/01/2020.

FOGAÇA, D. C.; TOGNATO, M.I. R.; MIQUELANTE, M. A. Reflexões de uma professora em formação inicial como participante do Pibid de Língua inglesa: relato de experiência. In: KRAWCZYK, A. C. de D. B.; GAGNO, R. R.; VIEIRA, L. A.; MACHADO, C. J. (Orgs.). Pibid e RP da Unespar: sobre esperançar em um período incerto para a docência. Paranavaí: Unespar, 2020.

GAGNON, R. ; SURIAN, M.. L'enseignement du français dans les plans de formation suisses romands: quels savoirs pour l'enseignement de la production écrite? Repère, n. 44, p. 93-115, 2011.

GERALDI, J.W. O ensino de língua portuguesa e a Base Nacional Comum Curricular. Rervista Retratos da Escola, Brasília, v. 9, n. 17, p. 381-396, jul./dez. 2015.

HOFSTETTER R.; SCHNEUWLY B. Savoirs en (trans)formation. Au cœur des professions de l'enseignement et de la formation. In: HOFSTETTER, R.; SCHNEUWLY, B. Savoirs en (trans)formations des savoirs dans les formations aux professions enseignantes. Bruxelles : De Boeck, 2009, p. 6-22.

LANFERDINI, P. A. da F.; CRISTOVÃO, V. L. L.. Uma proposta de elaboração de sequência didática para o ensino de LI e o desenvolvimento de capacidades de linguagem. Anais do VI SIGET - Simpósio Internacional de Estudos de Gêneros Textuais, 16 a 19 de agosto de 2011, Natal, RN. 18p.

LIBÂNEO, J. C. Formação de professores e didática para desenvolvimento humano. Educação E Realidade, Porto Alegre, v.40, n.2, p. 629-650, abr./jun. 2015.

MIQUELANTE, M. A. Saberes necessários à formação docente - articulação desafiadora a partir de sequências de formação, de ensino e didática como instrumentos mediadores. 2018. Tese de Doutorado. Universidade Estadual de Londrina, Londrina, 2019.

PINTO, S. M.; TOGNATO, M. I. R.; MIQUELANTE, M. A. Produção de atividades didáticas: uma experiência desafiadora proporcionada pelo Pibid de Língua Inglesa na formação inicial: relato de experiência. In: KRAWCZYK, A. C. de D. B.; GAGNO, R. R.; VIEIRA, L.

TOGNATO, M. I. R., BUTTLER, D. B. Resenhas dos livros didáticos aprovados pelo Guia do PNLD/2020 de língua portuguesa: uma ferramenta para 0 trabalho docente 
A.; MACHADO, C. J. (Orgs.). Pibid e RP da Unespar: sobre esperançar em um período incerto para a docência. Paranavaí: Unespar, 2020.

SCHNEUWLY, B.; DOLZ, J. Gêneros orais e escritos na escola. Trad. Roxane Rojo e Glais Sales Cordeiro. Campinas, SP: Mercado das Letras, 2004.

SILVA, R. C. da. O professor de línguas, o PNLD, o livro didático de línguas e outros materiais didáticos. Revista A Cor da Letras, v.18, n.3, p. 138-153, set.-dez de 2017. Disponível em: http:// periodicos.uefs.br/index.php/acordasletras/article/view/view/1788/pdf. Acesso em 06/02/20.

STUTZ, L. Sequências didáticas, socialização de diários e autoconfrontação: instrumentos para a formação inicial de professores de inglês. 2012. 458f. Tese (Doutorado em Estudos da Linguagem) - Universidade Estadual de Londrina, 2012.

STUTZ, L.; CRISTOVÃO, V. L. L . A construção de uma sequência didática na formação docente inicial de língua inglesa. Signum: Estudos da Linguagem, v. 14, p. 569, 2011.

TOGNATO, M.I.R.; OLIVEIRA, J. A. de. A sequência didática na formação inicial de professores de língua inglesa: escrita como processo e as capacidades docentes. Revista Interfaces, v.9, n.4, p. 186-200, out./nov./dez. 2018.

XAVIER, M. M.; ALMEIDA, M. F. A Base Nacional Comum Curricular e o Ensino de Língua Portuguesa. In: Anais do III Congresso Nacional de Educação. 2017.

Recebido: 20/02/2020.

Aprovado: 22/06/2020.

TOGNATO, M. I. R., BUTTLER, D. B. Resenhas dos livros didáticos aprovados pelo Guia do PNLD/2020 de língua portuguesa: uma ferramenta para 0 trabalho docente 